\section{Canadian Association of Gastroenterology launches human resources planning initiatives}

Desmond Leddin MB FRCPC

President, CAC

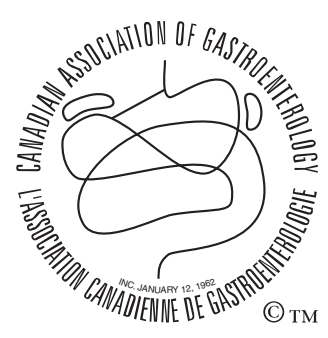

En français voir page 586
$\mathrm{I}_{\mathrm{cos}}^{\mathrm{n}}$ In 2002, the Canadian Association of Gastroenterology (CAG) conducted a survey of the membership, the results of which were reviewed and developed by the Past Presidents' Council into a long term strategic plan. Survey findings and the resulting strategic plan were published earlier this year in The Canadian Journal of Gastroenterology and can be reviewed on the CAG Web site at <http://www.pulsus.com/Gastro/18_01/Pdf/newe_ed.pdf> and <http://www.pulsus.com/Gastro/18_02/Pdf/newe_ed.pdf $>$. Members repeatedly noted the importance of collecting statistics on gastroenterology in Canada and addressing human resource issues.

The CAG has now undertaken a number of projects that will form the basis of a human resource plan for gastroenterology.

To date, this goal has proved elusive given the numerous challenges. One major problem is that the practice of gastroenterology does not have clearly defined boundaries. Only cardiovascular surgeons perform coronary artery bypass grafts, but a referral from a family doctor for a patient with rectal bleeding could be sent to a gastroenterologist, a general internist or a surgeon - to name but a few. In addition, the demand for gastroenterology services varies. There is evidence that referral rates are different for rural versus urban gastroenterology practices. Referral rates also depend on the number of family doctors in the referral area and on the burden of illness in the referral community. Furthermore, the appropriate number of gastroenterologists is a moving target. Over the past decade, changes in referral patterns for colonoscopy with the increase in colon cancer screening requests has led to very significant changes in practice profiles. Based on preliminary data from the CAG survey of Canadian gastroenterology practice, it now appears that many of us spend as much time doing colonoscopy as we do providing direct consultative services.

How can a plan be developed given these obstacles? After considerable deliberations, we have decided to take a page from the books of our radiological and cardiovascular colleagues, who have very effectively made their case for appropriate resources. A key part of their strategy involved defining appropriate wait times for access to their services and measurement of whether those standards were being met. Advantages of this approach are that it is built on consensus and applies a patient perspective to the problem. It is also in keeping with current federal and provincial government thinking. During the recent election the issue of wait times surfaced repeatedly, and government has committed to ensuring that access to the health care system is timely and appropriate.

Many regions and centres, including ours in Halifax, Nova Scotia, already work with guidelines on appropriate wait times, and schedule gastroenterology services based on these criteria. Every community-based gastroenterologist either formally or less formally triages their referrals based on acuity and need. For example, most of us would recognize that a patient with hematemesis needs to be seen very urgently while a patient who wishes to discuss elective screening colonoscopy can wait. However, the availability of national guidelines would provide a standard to target, and a means of identifying, existing shortfalls. Thus, one part of the CAG human resource project will include holding a consensus conference to develop evidence- and expertise-based recommendations on appropriate wait times.

The second part of the strategy involves measuring current wait times. The CAG, in partnership with AstraZeneca Canada Inc, has developed a personal audit system for physicians (practice audit in gastroenterology [PAGE]) that is now being used by other specialties and may be adopted internationally. The PAGE program arose from a desire to provide the CAG membership with innovative ways to earn credits through the Royal College of Physicians and Surgeons of Canada (RCPSC) maintenance of certification program. We are proposing to use PAGE to record actual wait times for gastroenterology consultation and diagnostic procedures across the country. Gastroenterologists will be asked to anonymously enter data into a pocket $\mathrm{PC}$ over a period of approximately one week. Information captured will include the indication for referral to the gastroenterologist, the time between referral and consultation, and the total time between referral and receipt of diagnostic services.

Actual wait times will then be compared with the consensus conference recommendations. In regions where the two are
Abbott Laboratories Ltd.
AstraZeneca Canada Inc.
Axcan Pharma Inc.
Janssen-Ortho Inc.
Pfizer Canada Inc. 
similar, we can conclude that the human resource situation is satisfactory. In areas where they are discrepant, solutions will need to be explored. The CAG proposes to support and augment the role of regional gastroenterology associations by providing the data they require to work with departments of health to find answers. It is recognized that the best approach for northern Ontario might be very different from that for Newfoundland or southern Alberta.

A third, equally important element of human resource planning involves understanding the available gastroenterology work force. The number of practicing gastroenterologists and whether they are working full- or part-time must be considered, along with factors that affect the flow of gastroenterologists into (training programs and immigration) and out of (retirement and emigration) the system. A subcommittee has been created to examine these demographics by reviewing all available databanks such as those of the Canadian Institutes of Health Information, the Canadian Medical Association, the RCPSC and the Canadian Post-MD Education Registry. This is vital if we are to understand and begin to plan for an appropriate number of gastroenterologists in Canada.

Human resources planning is an ambitious undertaking, but we are fortunate to have experienced and committed individuals leading the initiatives. CAG President-Elect Dr Bill Paterson will oversee the consensus on appropriate wait times. Dr Rob Hilsden, Dr Paul Moayyedi and Dr Linda Rabeneck have kindly agreed to mine the national databases regarding information on the number of available gastroenterologists. It will be my pleasure to lead the PAGE program to measure actual wait times, in association with the other members of the PAGE Committee (Dr David Armstrong, Dr Roger Hollingsworth, Dr Richard Hunt and Paul Sinclair). Project management and support will be provided by Sandra Daniels and Paul Sinclair in the CAG National Office.
The initiatives will run on a fairly tight timeline. We hope to begin measuring actual wait times in late 2004, and the consensus on desirable wait times will be held in early 2005. We will then spend some months analyzing the data and creating a national map intended to be presented in association with the World Congress of Gastroenterology in Montreal, Quebec in September 2005.

Having analyzed the current situation and trends, the focus will switch to generating solutions where required. We anticipate holding a meeting in association with Canadian Digestive Disease Week in February 2006 to discuss approaches to gastroenterology work force issues. Though that may seem a long way off there is much data gathering and planning to be done.

This is an ambitious undertaking. We have commitment from within the CAG to carry it forward and we need your commitment to help us to gather the required data. The project does not come without cost, and to this end we will be asking our partners to work with us to take this project to completion. As noted above, we have already gained industry support for the collection of wait list data. We hope that our partners, both industry and potentially government and affiliated groups such as the RCPSC, are as excited as we are and understand the importance of such initiatives for the overall maintenance and continued growth of gastroenterology in Canada.

As plans develop we will keep you apprised by posting updates on the CAG Web site. If you are a gastroenterology specialist, we ask you to support these efforts by signing up to participate in the PAGE program on wait times (http://www.cag-acg.org/sponsors/page.htm). Only with your support will we be successful in gathering the information needed to address the changing needs of patients and gastroenterology as a profession. 


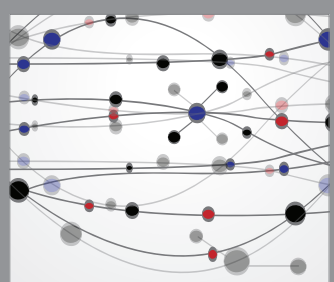

The Scientific World Journal
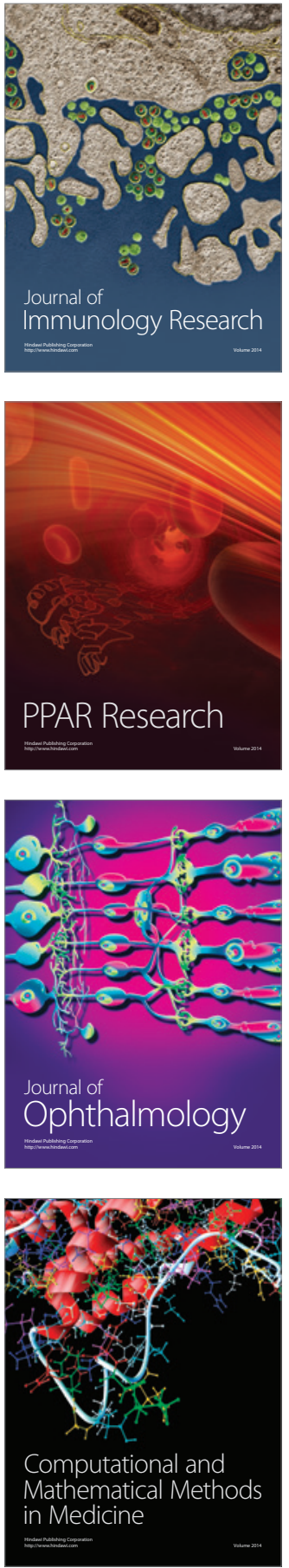

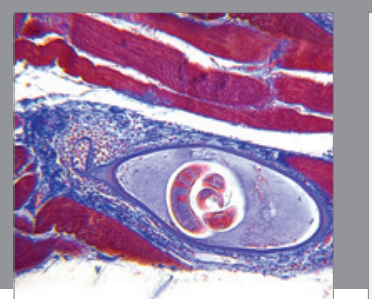

Gastroenterology Research and Practice

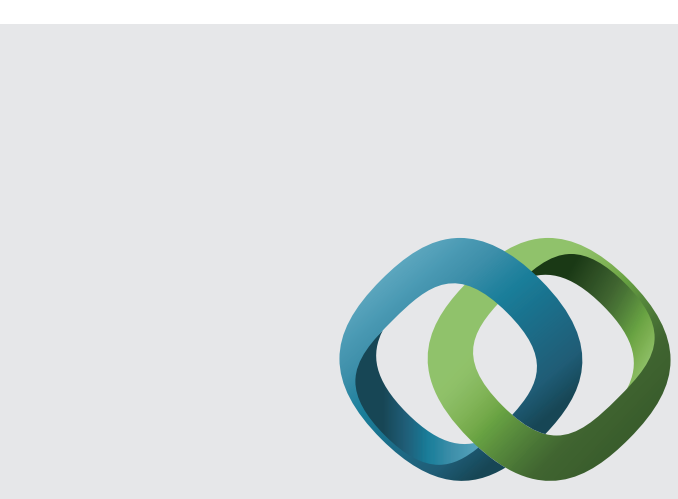

\section{Hindawi}

Submit your manuscripts at

http://www.hindawi.com
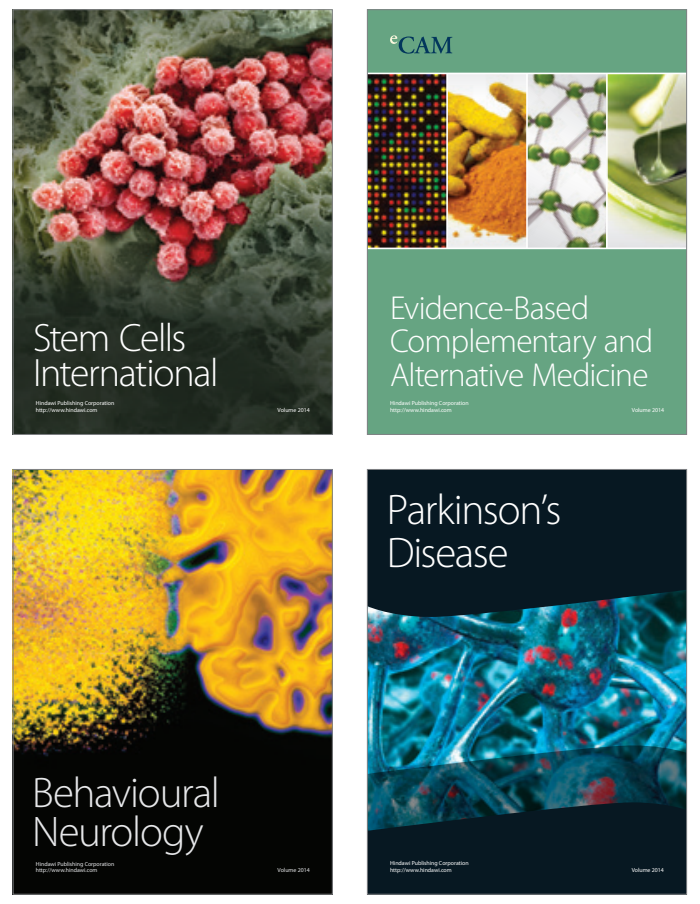
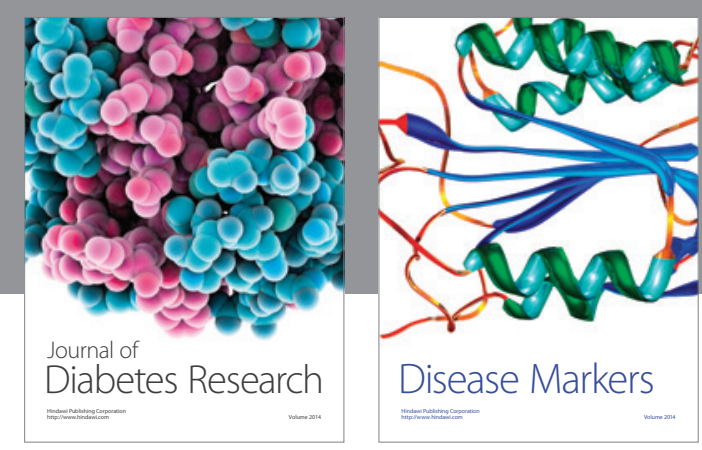

Disease Markers
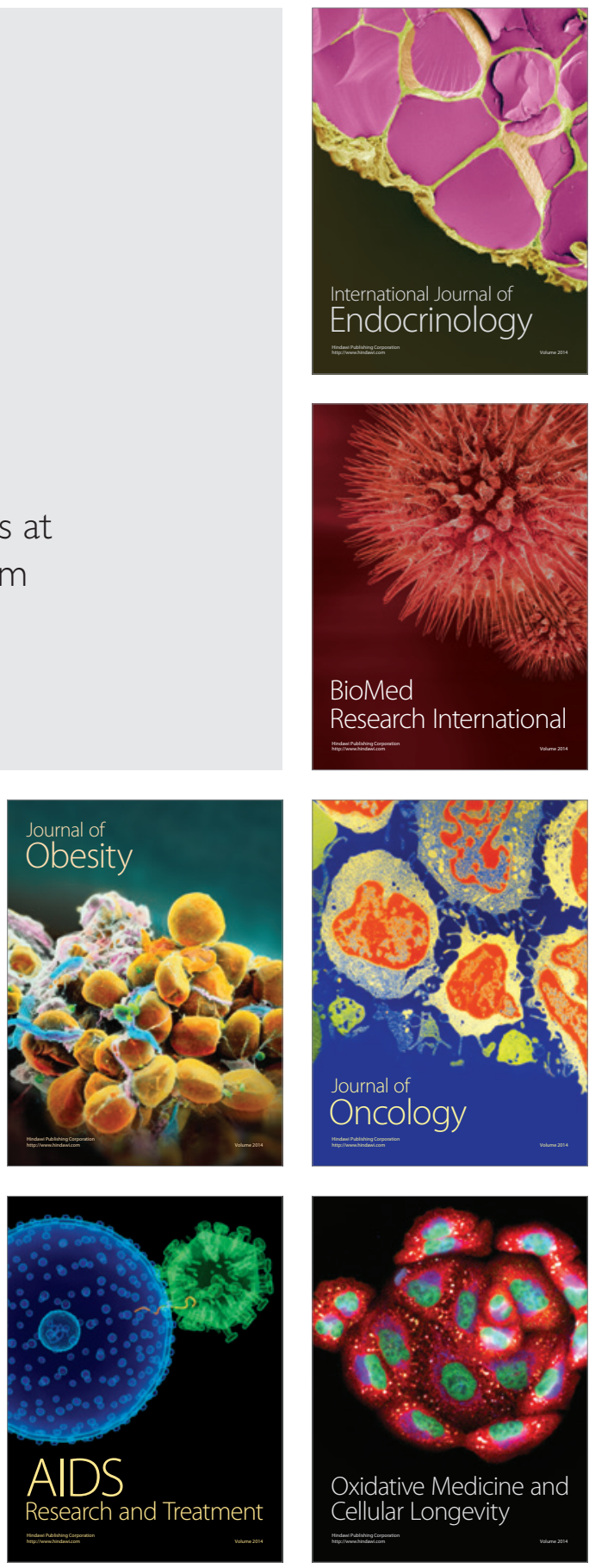